Article

\title{
Aging Characteristics of Rubber Modified Asphalts in Different Environmental Factors Combinations
}

\author{
Peng Xiao ${ }^{1}$, Jiahui Zheng ${ }^{1}$ (D), Aihong Kang ${ }^{1, *}$, Lu Sun ${ }^{2}$ and Yingqian Wang ${ }^{1}$ \\ 1 College of Civil Science and Engineering, Yangzhou University, Yangzhou 225009, Jiangsu, China; \\ xpyzu@163.com (P.X.); ZhengJH10@126.com (J.Z.); 1jennie2@sina.com (Y.W.) \\ 2 Department of Civil Engineering, Catholic University of America, 620 Michigan Ave NE, \\ Washington, DC 20064, USA; sunl@cua.edu \\ * Correspondence: kahyzu@163.com; Tel.: +86-138-1581-3548
}

Received: 30 June 2017; Accepted: 3 August 2017; Published: 7 August 2017

\begin{abstract}
Two kinds of rubber modified asphalts were investigated and compared with virgin asphalt. In order to get closer to engineering practice, different combinations of four environmental factors were merged into the laboratory aging simulation. Subsequently, conventional property tests, including softening point, viscosity, creep stiffness, creep rate, and fatigue cracking were conducted on asphalt samples. The performance difference of asphalt before and after aging was selected as an evaluation index for asphalt aging degree. The results indicate that two kinds of rubber modified asphalts show stronger resistant ability to temperature deformation and better resistance to traffic loading than virgin asphalt in all kinds of environmental factors combinations. Tests on chemical analyses were conducted to investigate the asphalt aging characteristics. The apparent morphology of rubber modified asphalts are described in detail under an environment scanning electron microscope (ESEM). The damage condition reflected in images reveals the aging degree caused by multiple environmental factors. Moreover, the thermogravimetric analysis (TG) confirms that three kinds of asphalts can maintain thermal stability in various environments. Additionally, new characteristic functional groups were not detected in the infrared (IR) spectra of rubber modified asphalts, which means they have stable antioxidant properties given that their oxidation degrees change slightly throughout the aging processes.
\end{abstract}

Keywords: rubber modified asphalts; environmental factors; aging characteristics; evaluation index; chemical analyses

\section{Introduction}

Two approaches are generally used to modify asphalts with vulcanized rubber powder, namely, physical and chemical modification. Numerous works have proven that physical modification can enhance the resistances to rutting at high temperatures and cracking at low temperatures [1-4]. Meanwhile, chemical modification, which is dependent on trans-polyoctenamer rubber (TOR), can further improve the workability and high temperature performance [5]. Moreover, rubber modified asphalts are regarded as environmentally friendly owing to their great consumption of waste tires [6]. Accordingly, employing these asphalts into pavement construction has become increasingly popular [7].

Mastering the aging characteristics of rubber modified asphalts tightly follows their promising prospects. However, comprehensive progress has yet to be achieved in this regard. Some research achievements on asphalt aging can be used for reference. It is confirmed that the aging of asphalt in service is mainly caused by the different environments to which the asphalt is subjected. From a chemical perspective, $\mathrm{Lu}$ and Siddiqui have concluded that thermal oxygen induces the formation of carbonyl and sulphoxide groups [8,9]. Lin proposed that carbonyl area index could be used as a 
chemical indicator to reflect the aging level of asphalt binder [10]. These polar functional groups in asphalt tend to aggregate and form complex and high-weight molecules, which are responsible for the increase in viscosity. Meanwhile, Calabi-Floody, and Apeagyei have held that oxidation is the chief cause of the hardening of asphalt binder, which further leads to the sharp degradation of durability and premature failure in service [11,12]. According to Wang, ultraviolet radiation is also a major cause of asphalt aging that results in the decay of fatigue resistance, increase in creep stiffness, and decline of failure strain [13]. Zeng suggested that working temperature of UV aging was under $50{ }^{\circ} \mathrm{C}$ [14]. Furthermore, Lv has proposed that the soluble substance in asphalt is susceptible to escape under rainfall, which also aggravates aging [15]. Therefore, the influences of different environmental factors should be considered to establish a comprehensive description for the aging characteristics of rubber modified asphalts.

The thin film oven test (TFOT) and pressurized aging vessel (PAV) test have been developed in the laboratory and standardized to simulate the thermal oxidative aging of modified asphalts (the tests also apply to rubber-modified asphalts) [16]. By contrast, the simulation of ultraviolet or water aging has received less attention. Fortunately, a few researchers have offered conversion methods for outdoor irradiation time, and pointed out that photochemical reaction has a significant effect on the surface of asphalt film [17-19]. In addition, Bian has introduced water molecules into the PAV test to study the asphalt degradation [20]. These suggestions undoubtedly provide inspiration for the design of aging simulations for the two rubber-modified asphalts in this study.

\section{Materials and Methods}

\subsection{Preparation Technology}

In this study, Jinling 70\# (mark number of asphalt) virgin asphalt (referred to as $\mathrm{P}$, as shown in Table 1) and Honglei rubber powder (60 mesh) were used to prepare rubber-modified asphalt (referred to as $\mathrm{R}$ ). This was a physical modification process, in which asphalt $\mathrm{P}$ was preheated to $170 \pm 3{ }^{\circ} \mathrm{C}$ and was mixed with the rubber powder ( $18 \%$ of the weight of the former) at a stirring rate of $500 \mathrm{rpm}$ for $60 \mathrm{~m}$. The mixture (asphalt R) then swelled in an oven at a constant temperature of $170{ }^{\circ} \mathrm{C}$ for $1 \mathrm{~h}$. Furthermore, TOR rubber modified asphalt (referred to as T) was obtained through TOR-dependent chemical modification, which was similar to the physical modification presented above. The recommended optimum amount of TOR to be mixed is measured as $4.5 \%$ of the weight of the rubber powder [21].

Table 1. Technical indices of asphalt $P$.

\begin{tabular}{ccc}
\hline Parameters & Standard Requirements & Results \\
\hline Penetration $/ 0.1 \mathrm{~mm}$ & $60 \sim 80$ & 74 \\
Softening point $/{ }^{\circ} \mathrm{C}$ & $\nless 45$ & 46.6 \\
Ductility $\left(10^{\circ} \mathrm{C}\right) / \mathrm{cm}$ & $\nless 15$ & 39 \\
Ductility $\left(15^{\circ} \mathrm{C}\right) / \mathrm{cm}$ & $\nless 100$ & $>150$ \\
\hline
\end{tabular}

\subsection{Test Scheme}

\subsubsection{Environmental Combinations}

Asphalts $\mathrm{R}$ and $\mathrm{T}$ were regarded as research objects and compared with asphalt $\mathrm{P}$. To reflect the actual aging process of asphalt in pavements and to improve the laboratory aging simulation, some self-designed combinations of environmental factors were merged into the aging simulation, as shown in Table 2.

Unaged Stage (Referred to as A)

The asphalt in the unaged stage served as a control group, which helped the test analyses. 
Short-Term Thermal Oxidative Aging (Referred to as B)

The thin film oven test (TFOT) was performed to simulate the short-term aging behavior of asphalt when mixed and paved in the construction stage. It was conducted at $163 \pm 1{ }^{\circ} \mathrm{C}$ for $5 \mathrm{~h}$ according to JTG E20 T 0609-2011 [16].

Thermal Oxygen and Ultraviolet Aging (Referred to as C)

The asphalt aging process induced by ultraviolet radiation was simulated using the ultraviolet aging instrument, which was equipped with several high-pressure GHF125W-03-type mercury lamps with a $365 \mathrm{~nm}$ wavelength. Following TFOT, each asphalt sample was placed in the instrument at $40 \pm 3{ }^{\circ} \mathrm{C}$ for $28 \mathrm{~h}$, irradiated at an intensity of $1.949 \times 104 \mu \mathrm{W} / \mathrm{cm}^{2}$. The test conditions were derived from the conversion of Shanghai outdoor radiation in July [22].

Long-Term Thermal Oxidative Aging (Referred to as D)

The pressurized aging vessel (PAV) test was conducted to simulate the oxidative aging reaction of asphalt during long-term service. With reference to JTG E20 T 0630-2011, the test was conducted at the temperature of $100 \pm 0.5{ }^{\circ} \mathrm{C}$ and air pressure of $2.1 \pm 0.1 \mathrm{Mpa}$ for $20 \mathrm{~h} \pm 10 \mathrm{~m}$ after TFOT [16].

Thermal Oxygen and Water Aging (Referred to as E)

The mode of water action was introduced into the PAV test to simulate the thermal oxygen and water aging of asphalt. This simulation test was conducted after TFOT and basically in accordance with the PAV test, except that in the first $1 / 3$ of the test stage (which conformed to the ratio of average annual rainy days), water at $10 \%$ the weight of the asphalt was used in the aging reaction.

Thermal Oxygen, Water, and Ultraviolet Aging (Referred to as F)

The asphalt samples were successively aged by TFOT, PAV test (with water action) and ultraviolet radiation $\left(40 \pm 3{ }^{\circ} \mathrm{C}, 28 \mathrm{~h}\right)$ to simulate the aging process in a multi-factor environment.

Table 2. Aging conditions.

\begin{tabular}{cc}
\hline Sequence Number & Aging Conditions \\
\hline Condition A (Unaged stage) & - \\
\hline Condition B (Short-term thermal oxidative aging) & $163^{\circ} \mathrm{C}$ \\
$5 \mathrm{~h}$
\end{tabular}

\subsubsection{Test Methods for Property Characterization}

No index could directly reflect the aging characteristic of the asphalt. However, the extent of change in asphalt properties was related to aging and could be an indirect evaluation index. Moreover, each property was characterized by its corresponding index. Therefore, tests for representative technical indices and chemical indices were conducted, as shown in Table 3. 
Table 3. Test methods.

\begin{tabular}{cc}
\hline Indices & Test Methods \\
\hline Technical indices & Softening point \\
Viscosity \\
& Creep stiffness \\
& Creep rate \\
& Fatigue cracking factor \\
\hline Chemical indices & SEM analysis \\
& Thermogravimetric analysis \\
& IR spectrum analysis \\
\hline
\end{tabular}

Tests for Technical Indices

To describe the resistant ability to high temperature, the softening point and viscosity $\left(170{ }^{\circ} \mathrm{C}\right)$ were tested with reference to JTG E20 T 0606-2011 and JTG E20 T 0625-2011, respectively. The low-temperature resistance of asphalt was represented by creep stiffness and creep rate $\left(-12{ }^{\circ} \mathrm{C}\right)$, which were measured with a bending beam rheometer (BBR) (Cannon Instrument Company, State College, PA, USA) according to JTG E20 T 0627-2011. Moreover, the fatigue cracking factors $\left(25^{\circ} \mathrm{C}\right.$, $19^{\circ} \mathrm{C}$ ) were obtained with a dynamic shear rheometer (DSR) (Malvern Instruments Ltd., Shanghai, China) and were used to characterize the fatigue resistance of asphalt. In accordance with JTG E20 T 0628-2011, the test was conducted at a fixed frequency of $10 \mathrm{rad} / \mathrm{s}$ [16].

Tests for Chemical Indices

Tests for chemical indices were used to investigate the aging characteristics of asphalt further. The apparent morphology of aged asphalt was observed with the PHLIPS XL-30 environment scanning electron microscope (ESEM) (Royal Dutch Philips Electronics Ltd., Amsterdam, The Netherlands) at a micro level. A TG analyzer (PerkinElmer Ltd., Middlesex County, MA, USA) was used in the thermal stability analysis. Approximately $10 \mathrm{mg}$ of each sample were heated from $25^{\circ} \mathrm{C}$ to $500^{\circ} \mathrm{C}$ at a speed of $10^{\circ} \mathrm{C} / \mathrm{m}$. In addition, infrared (IR) absorption spectra ranging from $4000 \mathrm{~cm}^{-1}$ to $500 \mathrm{~cm}^{-1}$ were acquired with a Cary 610/670 microscopic infrared spectrometer (Varian Co. Ltd., Salt Lake City, UT, USA) for functional group analysis.

\section{Results and Discussion}

\subsection{Evaluation Index for Aging Characteristics}

With respect to the contrast and analysis of aging characteristics for all kinds of asphalts, the value of the difference between before and after aging is commonly referred to as an evaluation index. However, each kind of asphalt follows a unique aging law with regard to the same technical property when element components and colloidal structures vary. As a result, this index lacks comparability and minor revisions may be necessary. Instead, a relative index should be applied to contrast various asphalts. Thus, a kind of relative ratio $(r)$ which is calculated using Equation (1) is recommended for the evaluation of aging characteristics throughout this study:

$$
r=\left|\frac{X-X_{0}}{X_{0}}\right|
$$

where $X$ is a property index value under any environmental combination $(B, C, D, E$, or $F)$ and $X_{0}$ is the corresponding property index value in the unaged stage (A). Hence, $r$ represents the aging degrees of the asphalt property; a slight extent indicates high adaptability to this environmental combination. 
The difference in the $r$ values of two given environmental combinations lies in the superposition of additional factors and can essentially imply adaptability to these factors. Accordingly, the detailed realization forms are listed in Table 4.

Table 4. Adaptability to environmental factors.

\begin{tabular}{|c|c|c|c|c|}
\hline Combination and Factor & $\Delta_{C B}$ & $\Delta_{D B}$ & $\Delta_{E D}$ & $\Delta_{F E}$ \\
\hline B: short-term TO & \multirow{5}{*}{$\begin{array}{c}\mathrm{C}-\mathrm{B} \\
\text { Adaptability } \\
\text { to UR }\end{array}$} & \multirow{5}{*}{$\begin{array}{c}\mathrm{D}-\mathrm{B} \\
\text { Adaptability } \\
\text { to long-term } \\
(\mathrm{TO}+\mathrm{AP})\end{array}$} & \multirow{5}{*}{$\begin{array}{c}\mathrm{E}-\mathrm{D} \\
\text { Adaptability } \\
\text { to WM }\end{array}$} & \multirow{5}{*}{$\begin{array}{c}\mathrm{F}-\mathrm{E} \\
\text { Adaptability } \\
\text { to UR }\end{array}$} \\
\hline C: short-term TO + UR & & & & \\
\hline D: short-term TO + long-term $(\mathrm{TO}+\mathrm{AP})$ & & & & \\
\hline $\mathrm{E}:$ short-term $\mathrm{TO}+$ long-term $(\mathrm{TO}+\mathrm{AP})+\mathrm{WM}$ & & & & \\
\hline F: short-term $\mathrm{TO}+$ long-term $(\mathrm{TO}+\mathrm{AP})+\mathrm{WM}+\mathrm{UR}$ & & & & \\
\hline
\end{tabular}

\subsection{Technical Indices Analysis}

\subsubsection{Softening Point Analysis}

The softening points of three kinds of asphalts $(\mathrm{P}, \mathrm{R}$, and $\mathrm{T})$ under different environmental combinations are displayed in Figure 1a. Their corresponding values are presented in Table 5. As observed in Figure 1a, the combination of environmental factors in turn increases the softening point. This result indicates that thermal oxidation, ultraviolet radiation, and water molecule are factors in asphalt aging. Moreover, asphalts $\mathrm{R}$ and $\mathrm{T}$ are clearly superior to asphalt $\mathrm{P}$ with respect to the resistant ability to temperature deformation given that the $r$ values of asphalts $\mathrm{R}$ and $\mathrm{T}$ in Table 5 are significantly lower than those of asphalt $P$ under any environmental combination. Table 5 illustrates further that asphalt $\mathrm{R}$ prevents the deformation in high temperature more effectively than the other two kinds of asphalts under water action because its $\Delta r_{E D}$ value is the lowest among the three. Similarly, the contrast results of $\Delta r_{D A}$ values suggest that the resistant ability to temperature deformation of asphalt $\mathrm{T}$ is better than the other two kinds of asphalts in the thermal oxidative environment.

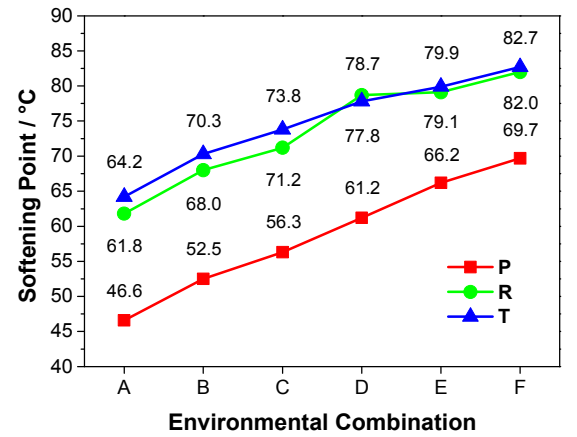

(a)

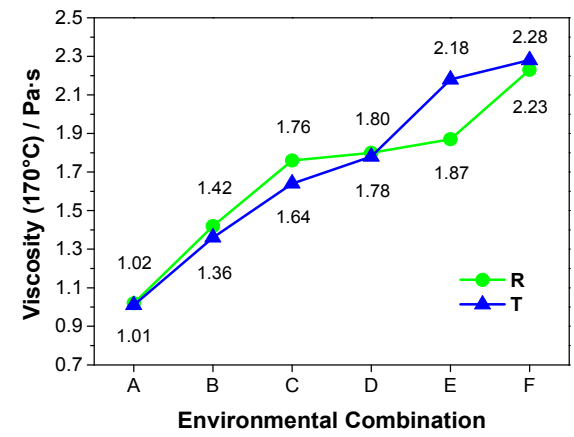

(b)

Figure 1. (a) Softening points of three kinds of asphalts under different environmental combinations.

(b) Viscosities of two kinds of asphalts under different environmental combinations.

Table 5. $r$ and $\Delta r$ values of softening points.

\begin{tabular}{cccccccccc}
\hline Sample & $r_{\boldsymbol{B}}$ & $r_{C}$ & $r_{\boldsymbol{D}}$ & $\boldsymbol{r}_{\boldsymbol{E}}$ & $\boldsymbol{r}_{\boldsymbol{F}}$ & $\boldsymbol{\Delta} \boldsymbol{r}_{C B}$ & $\boldsymbol{\Delta} \boldsymbol{r}_{\boldsymbol{D A}}$ & $\boldsymbol{\Delta} \boldsymbol{r}_{E \boldsymbol{D}}$ & $\boldsymbol{\Delta} \boldsymbol{r}_{\boldsymbol{F}}$ \\
\hline Asphalt P & 0.1266 & 0.2082 & 0.3133 & 0.4206 & 0.4957 & 0.0815 & 0.3133 & 0.1073 & 0.0751 \\
Asphalt R & 0.1003 & 0.1521 & 0.2735 & 0.2799 & 0.3269 & 0.0518 & 0.2735 & 0.0065 & 0.0469 \\
Asphalt T & 0.0950 & 0.1495 & 0.2118 & 0.2445 & 0.2882 & 0.0545 & 0.2118 & 0.0327 & 0.0436 \\
\hline
\end{tabular}




\subsubsection{Viscosity Analysis}

Wang actually confirms that the viscosity of unmodified asphalt is distinctly low at $170{ }^{\circ} \mathrm{C}$ [4]. Thus, Figure $1 \mathrm{~b}$ and Table 6 merely present the contrasts between asphalt $\mathrm{R}$ and $\mathrm{T}$ under different environmental combinations. As shown in Table 6, the deformation of asphalt $\mathrm{R}$ in temperature remains quite small in the environment, which is dominated by water molecules because the related $\Delta r_{E D}$ value is rather low. This finding corresponds to that of softening point analysis. Moreover, the deformation of asphalt $\mathrm{T}$ in high temperature tends to change slightly under ultraviolet radiation, as represented by the low $\Delta r_{C B}$ and $\Delta r_{F E}$ values. The restraint on viscosity growth and the strong resistant ability to temperature deformation are fully achieved by the regulating action of TOR, which may account for the result described above.

Table 6. $r$ and $\Delta r$ values of viscosities.

\begin{tabular}{cccccccccc}
\hline Sample & $r_{\boldsymbol{B}}$ & $\boldsymbol{r}_{\boldsymbol{C}}$ & $\boldsymbol{r}_{\boldsymbol{D}}$ & $\boldsymbol{r}_{\boldsymbol{E}}$ & $\boldsymbol{r}_{\boldsymbol{F}}$ & $\boldsymbol{\Delta} \boldsymbol{r}_{\boldsymbol{C B}}$ & $\boldsymbol{\Delta} \boldsymbol{r}_{\boldsymbol{D A}}$ & $\Delta \boldsymbol{r}_{\boldsymbol{E D}}$ & $\boldsymbol{\Delta} \boldsymbol{r}_{\boldsymbol{F}}$ \\
\hline Asphalt R & 0.3922 & 0.7255 & 0.7647 & 0.8333 & 1.1863 & 0.3333 & 0.7647 & 0.0686 & 0.3529 \\
Asphalt T & 0.3465 & 0.6238 & 0.7624 & 1.1584 & 1.2574 & 0.2772 & 0.7624 & 0.3960 & 0.0990 \\
\hline
\end{tabular}

\subsubsection{Creep Stiffness and Creep Rate Analyses}

As depicted in Figure 2, the creep stiffness and creep rate lines extend in opposite directions based on the combination of environmental factors, which are applied to each asphalt sample at $-12{ }^{\circ} \mathrm{C}$. On the one hand, the addition of rubber powder markedly reduces the creep stiffness and creep rate of asphalt. On the other hand, TOR lowers the creep stiffness further but increases the creep rate slightly after being mixed into asphalt. According to Table 7, the possibility of low-temperature resistance decline is extremely low for asphalt R given that its $r$ values of stiffness and rate are both low regardless of the environmental combination. Moreover, the $\Delta r_{D A}$ values of stiffness and rate in asphalts $\mathrm{P}$ and $\mathrm{T}$ are much higher than those in asphalt $\mathrm{R}$, thereby indicating that the low-temperature resistance of the latter rarely decays in the thermal oxidative environment. Based on the contrasts of $\Delta r_{E D}$ values, asphalts $\mathrm{P}$ and $\mathrm{R}$ differ negligibly with respect to the variation degree of creep rate when influenced by water molecules; nonetheless, asphalt $\mathrm{R}$ shows better ability in low-temperature resistance because of its slighter variation in creep stiffness.

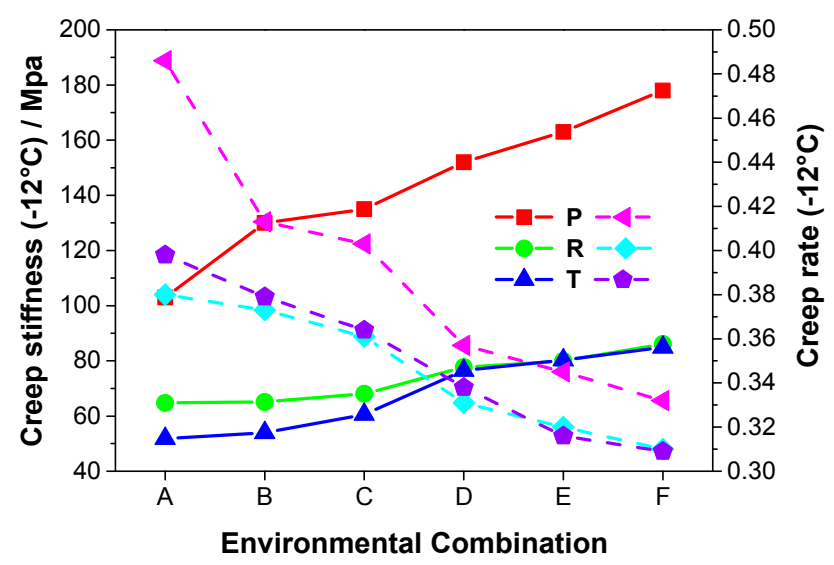

Figure 2. Creep stiffness and creep rate lines of three kinds of asphalts $(\mathrm{P}, \mathrm{R}$, and $\mathrm{T})$ under different environmental combinations. 
Table 7. $r$ and $\Delta r$ values of creep stiffness and creep rate at $-12{ }^{\circ} \mathrm{C}$.

\begin{tabular}{ccccccccccc}
\hline Indices & Sample & $r_{B}$ & $r_{C}$ & $r_{D}$ & $r_{E}$ & $r_{F}$ & $\Delta r_{C B}$ & $\Delta r_{D A}$ & $\Delta r_{E D}$ & $\Delta r_{F E}$ \\
\hline \multirow{3}{*}{ Creep stiffness } & Asphalt P & 0.2621 & 0.3107 & 0.4757 & 0.5825 & 0.7282 & 0.0485 & 0.4757 & 0.1068 & 0.1456 \\
& Asphalt R & 0.0046 & 0.0509 & 0.1991 & 0.2346 & 0.3287 & 0.0463 & 0.1991 & 0.0355 & 0.0941 \\
& Asphalt T & 0.0405 & 0.1699 & 0.4768 & 0.5502 & 0.6390 & 0.1293 & 0.4768 & 0.0734 & 0.0888 \\
\hline \multirow{3}{*}{ Creep rate } & Asphalt P & 0.1502 & 0.1708 & 0.2654 & 0.2901 & 0.3169 & 0.0206 & 0.2654 & 0.0247 & 0.0268 \\
& Asphalt R & 0.0184 & 0.0500 & 0.1290 & 0.1579 & 0.1842 & 0.0316 & 0.1290 & 0.0290 & 0.0263 \\
& Asphalt T & 0.0477 & 0.0854 & 0.1508 & 0.2060 & 0.2236 & 0.0377 & 0.1508 & 0.0553 & 0.0176 \\
\hline
\end{tabular}

\subsubsection{Fatigue Cracking Factor $\left(G^{*} \cdot \sin \delta\right)$ Analysis}

As exhibited in Figure 3, the $G^{*} \cdot \sin \delta$ line in each kind of asphalt trends upward with the combination of environmental factors at either $25^{\circ} \mathrm{C}$ or $19^{\circ} \mathrm{C}$. As shown in Figure $3 \mathrm{a}, \mathrm{b}, \mathrm{G}^{*} \cdot \sin \delta$ of asphalt $\mathrm{P}$ was larger than the others under each environmental combination, this indicated that two kinds of rubber modified asphalt had better resistance to traffic loading under the same condition. It can be seen in Table 8 that $r$ values of asphalt $R$ are lower than asphalt $P$ and $T$. This proved that although asphalt $\mathrm{R}$ had experienced aging, it had higher adaptability to traffic loading than the others. Several other conclusions can be reached from Table 8: Firstly, asphalt $\mathrm{T}$ displays relatively stable resistance to traffic loading when influenced by water molecules, as per its low $\Delta r_{E D}$ values at $25{ }^{\circ} \mathrm{C}$ and $19^{\circ} \mathrm{C}$. Secondly, the resistance to traffic loading of asphalt $\mathrm{R}$ declines slightly under ultraviolet radiation based on the contrasts of $\Delta r_{C B}$ and $\Delta r_{F E}$ values.

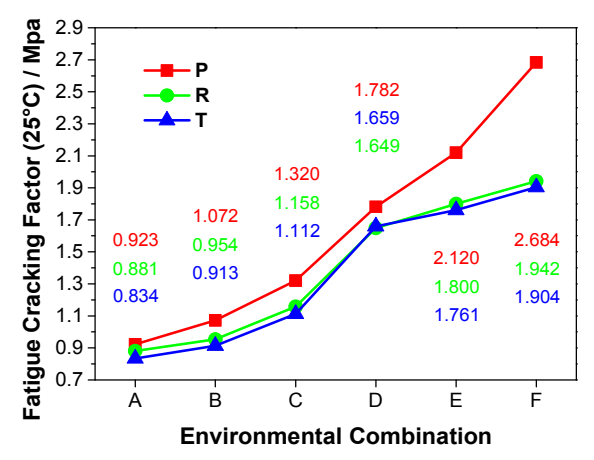

(a)

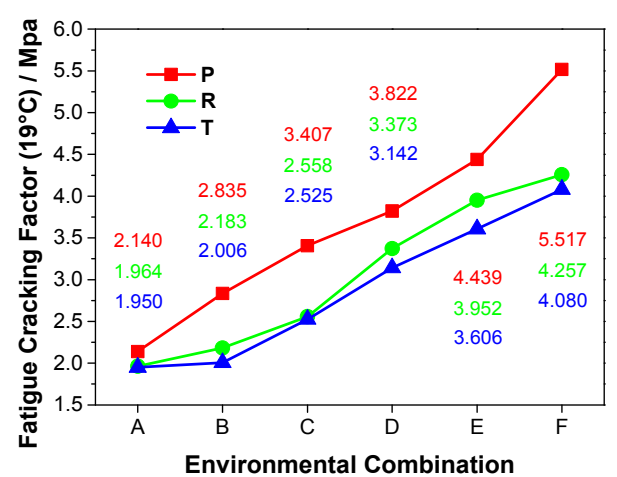

(b)

Figure 3. Fatigue cracking factors of three kinds of asphalts $(\mathrm{P}, \mathrm{R}$, and $\mathrm{T})$ under different environmental combinations: (a) at $25^{\circ} \mathrm{C}$; and (b) at $19{ }^{\circ} \mathrm{C}$.

Table 8. $r$ and $\Delta r$ values of fatigue cracking factors at $25^{\circ} \mathrm{C}$ and $19^{\circ} \mathrm{C}$.

\begin{tabular}{ccccccccccc}
\hline Temperature & Sample & $r_{\boldsymbol{B}}$ & $r_{\boldsymbol{C}}$ & $r_{\boldsymbol{D}}$ & $\boldsymbol{r}_{\boldsymbol{E}}$ & $\boldsymbol{r}_{\boldsymbol{F}}$ & $\Delta \boldsymbol{r}_{C B}$ & $\Delta \boldsymbol{r}_{\boldsymbol{D} A}$ & $\Delta \boldsymbol{r}_{E D}$ & $\Delta \boldsymbol{r}_{F E}$ \\
\hline \multirow{3}{*}{$25^{\circ} \mathrm{C}$} & Asphalt P & 0.1614 & 0.4301 & 0.9307 & 1.2969 & 1.9079 & 0.2687 & 0.9307 & 0.3662 & 0.6111 \\
& Asphalt R & 0.0829 & 0.3144 & 0.8717 & 1.0431 & 1.2043 & 0.2316 & 0.8717 & 0.1714 & 0.1612 \\
& Asphalt T & 0.0947 & 0.3333 & 0.9892 & 1.1115 & 1.2830 & 0.2386 & 0.9892 & 0.1223 & 0.1715 \\
\hline \multirow{3}{*}{$19^{\circ} \mathrm{C}$} & Asphalt P & 0.3248 & 0.5921 & 0.7860 & 1.0743 & 1.5780 & 0.2673 & 0.7860 & 0.2883 & 0.5037 \\
& Asphalt R & 0.1115 & 0.3024 & 0.7174 & 1.0122 & 1.1675 & 0.1909 & 0.7174 & 0.2948 & 0.1553 \\
& Asphalt T & 0.0287 & 0.2949 & 0.6113 & 0.8492 & 1.0923 & 0.2662 & 0.6113 & 0.2379 & 0.2431 \\
\hline
\end{tabular}

\subsection{Chemical Indices Analyses}

\subsubsection{SEM Analysis}

Based on the test proof, soft asphalt $\mathrm{P}$ cannot endure the high penetrating power of ion beams. In addition, asphalts $\mathrm{R}$ and $\mathrm{T}$ subject to combinations $\mathrm{A}, \mathrm{B}$, and $\mathrm{C}$ can hardly be distinguished from one 
another due to their faint changes. Therefore, the SEM images of asphalts $\mathrm{R}$ and $\mathrm{T}$ under combinations $D, E$, and $F$ are retained.

In Figure 4, holes are scattered across the asphalt surface. This observation implies a severe degree of ageing induced by combination D. Moreover, the apparent morphologies of asphalts $\mathrm{R}$ and $\mathrm{T}$ are highly similar.

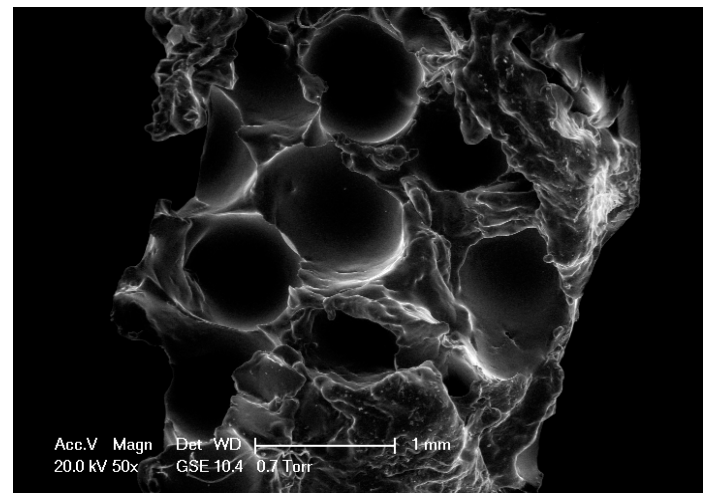

(a)

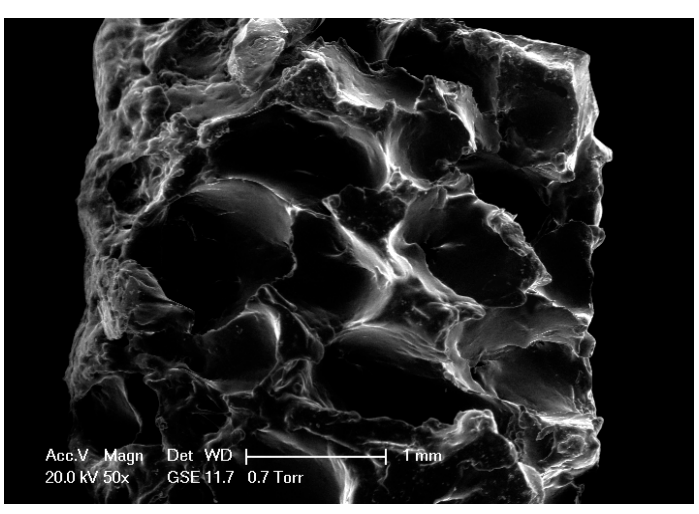

(b)

Figure 4. Apparent morphologies of two kinds of asphalts ( $R$ and $T$ ) under combination $D$ : (a) Asphalt R; and (b) Asphalt T.

The holes of asphalts $\mathrm{R}$ and $\mathrm{T}$ are enlarged to a certain extent, as shown in Figure 5 under combination $\mathrm{E}$. The detrimental effect of combination $\mathrm{E}$ on asphalt aging is stronger than that of combination $\mathrm{D}$ with regard to the damaged condition of asphalt morphology.

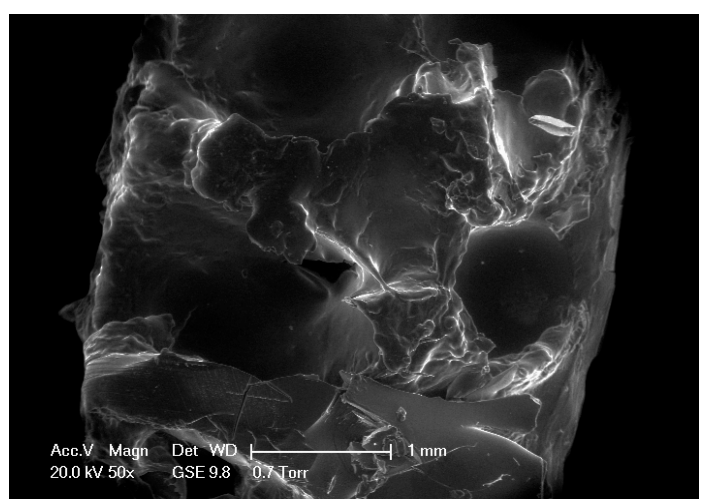

(a)

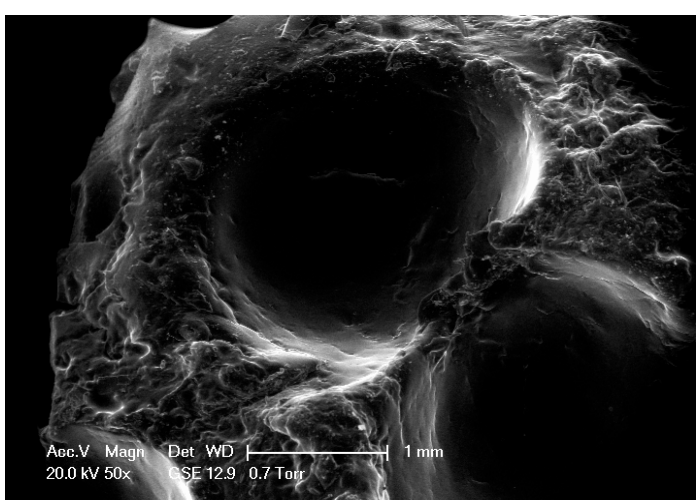

(b)

Figure 5. Apparent morphologies of two kinds of asphalts (R and T) under combination E: (a) Asphalt R; and (b) Asphalt T.

It can be preliminarily inferred that the asphalt under combination $\mathrm{F}$ is the most damaged. The damaged areas under a high power field are described in detail in Figure 6. Multi-level folds and corrosional flutes comprise the rough morphologies of asphalts $\mathrm{R}$ and $\mathrm{T}$, and these compositions intuitively reveal asphalt decays. 


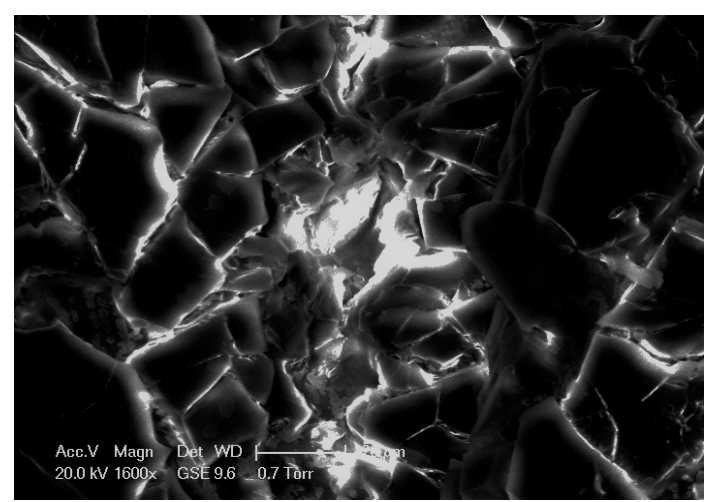

(a)

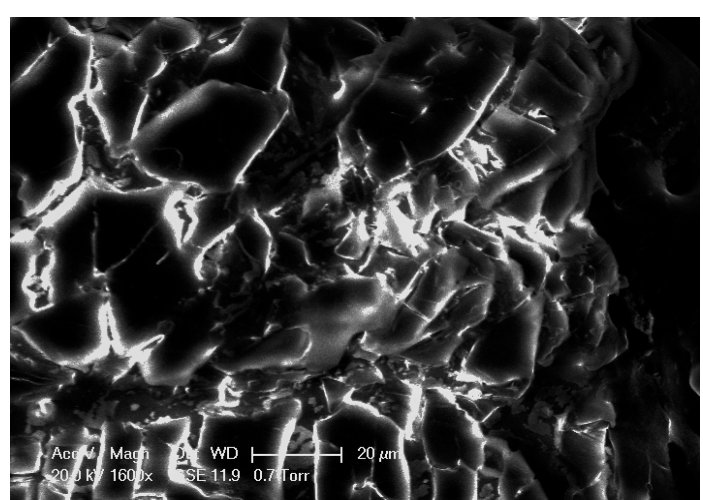

(b)

Figure 6. Apparent morphologies of two kinds of asphalts ( $R$ and $T$ ) under combination F: (a) Asphalt R; and (b) Asphalt T.

\subsubsection{Thermogravimetric Analysis}

In consideration of the manufacturing process and serving condition of asphalt, the TG curves of asphalts $\mathrm{P}, \mathrm{R}$, and $\mathrm{T}$ under combinations $\mathrm{A}, \mathrm{B}, \mathrm{D}$, and $\mathrm{F}$ are retained.

A TG analyzer is a simple tool with which to study the thermal stabilities of asphalt. The TG versus temperature curves were used to evaluate the thermal stabilities of asphalts, respectively. A high mass-loss temperature denotes good thermal stability. The descending range of TG curves represents material decomposition.

The TG test results of the three kinds of asphalts under combinations $\mathrm{A}, \mathrm{B}, \mathrm{D}$, and $\mathrm{F}$ are displayed in Figure 7. It is evident from Figure 8 that asphalts $\mathrm{P}, \mathrm{R}$, and $\mathrm{T}$ do not decompose before $200{ }^{\circ} \mathrm{C}$, which indicates that various environment factors make no difference on asphalt during service temperatures. Moreover, there is no obvious change in TG curves about asphalt P, R, and T, which manifest that three kinds of asphalts maintain thermal stabilities under different combinations of environmental factors.

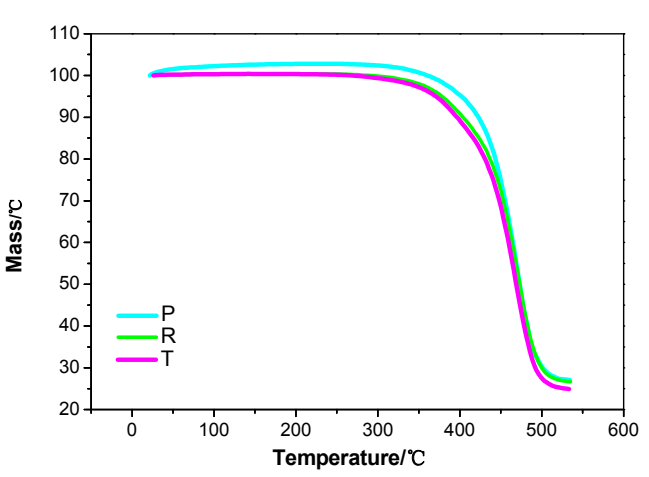

(a)

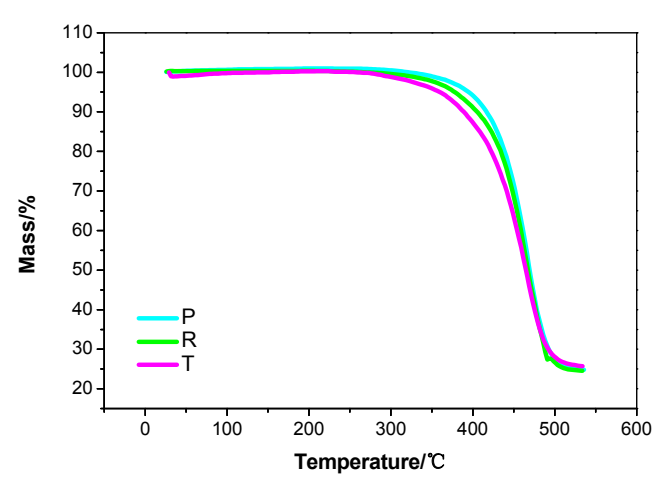

(b)

Figure 7. Cont. 


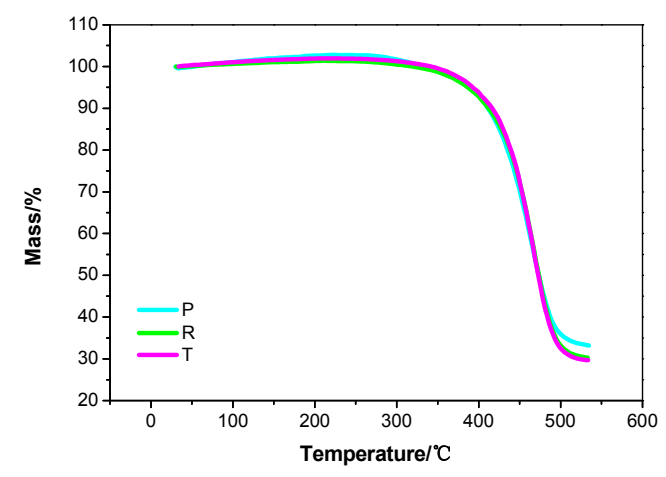

(c)

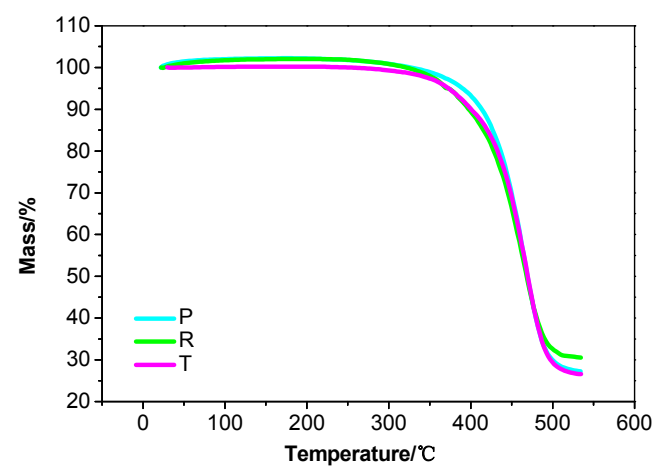

(d)

Figure 7. TG analyzer results of three kinds of asphalts $(\mathrm{P}, \mathrm{R}$, and $\mathrm{T})$ under different environmental combinations: (a) under combination A; (b) under combination $\mathrm{B}$; (c) under combination D; and (d) under combination F.

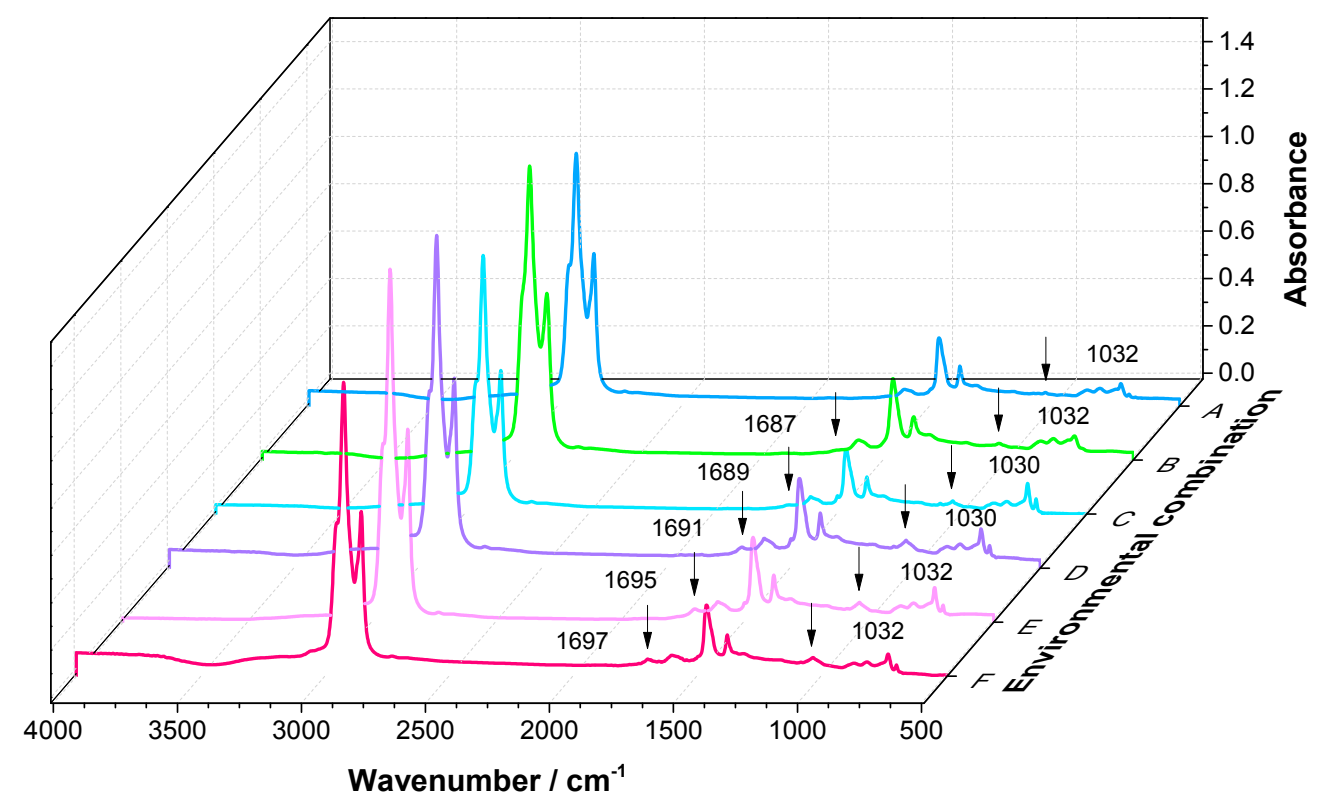

Figure 8. IR spectra of asphalt P under different environmental combinations.

\subsubsection{IR Spectrum Analysis}

As described in Figures 8-10, all of the typical bands are generally similar regardless of asphalt type and environmental combination. The strong absorption peaks at 2920 and $2850 \mathrm{~cm}^{-1}$ correspond to the stretching $\mathrm{C}-\mathrm{H}$ bonds and demonstrate the presence of $=\mathrm{CH} 2$ and $-\mathrm{CH}$. Moreover, the in-plane bending vibrations of $\mathrm{C}-\mathrm{H}$ bonds at 1460 and $1375 \mathrm{~cm}^{-1}$ can be an additional proof. Absorption peaks also expand at $1700 \mathrm{~cm}^{-1}$ as a result of stretching $\mathrm{C}=\mathrm{O}$ bonds, and the adjacent peaks which appear at $1600 \mathrm{~cm}^{-1}$ belong to the $\mathrm{C}=\mathrm{C}$ bonds in benzene. In addition, the stretches of $\mathrm{S}=\mathrm{O}$ bonds are observed at $1030 \mathrm{~cm}^{-1}$. 


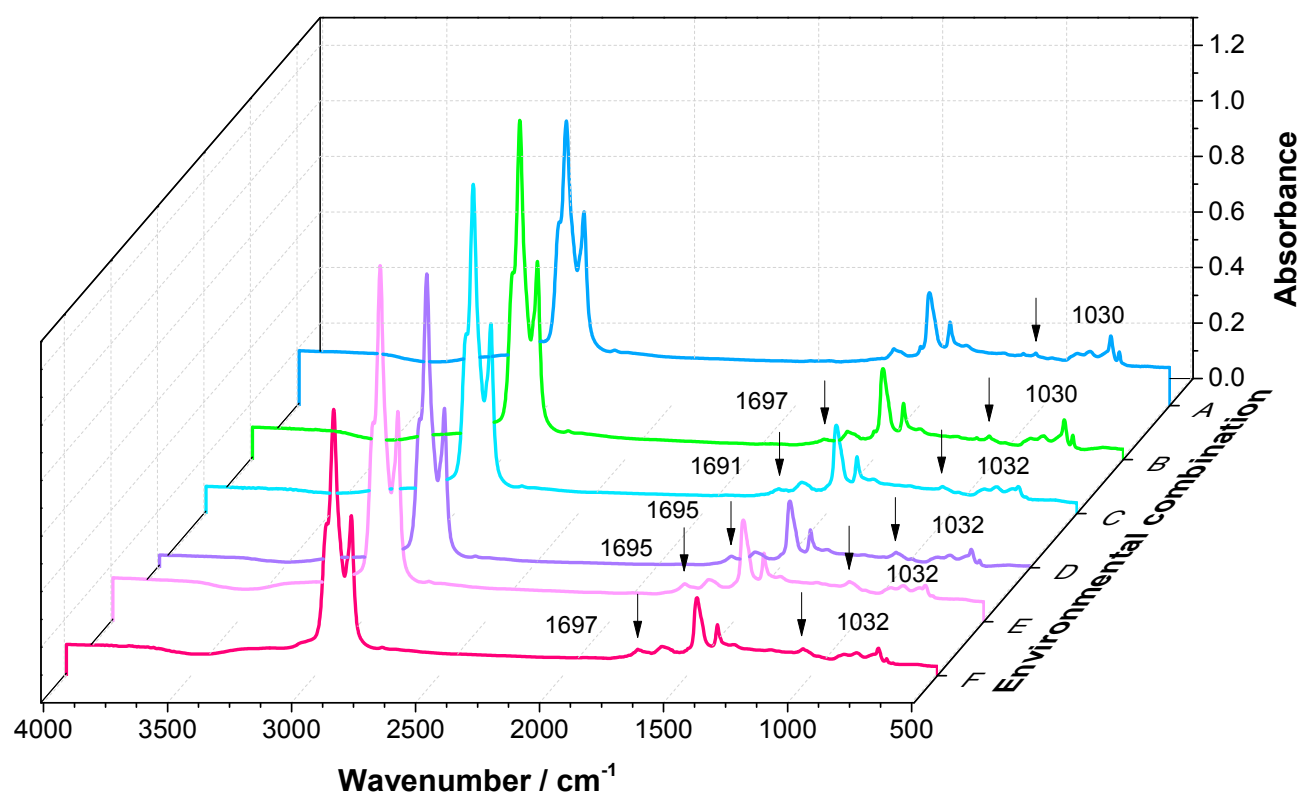

Figure 9. IR spectra of asphalt $\mathrm{R}$ under different environmental combinations.

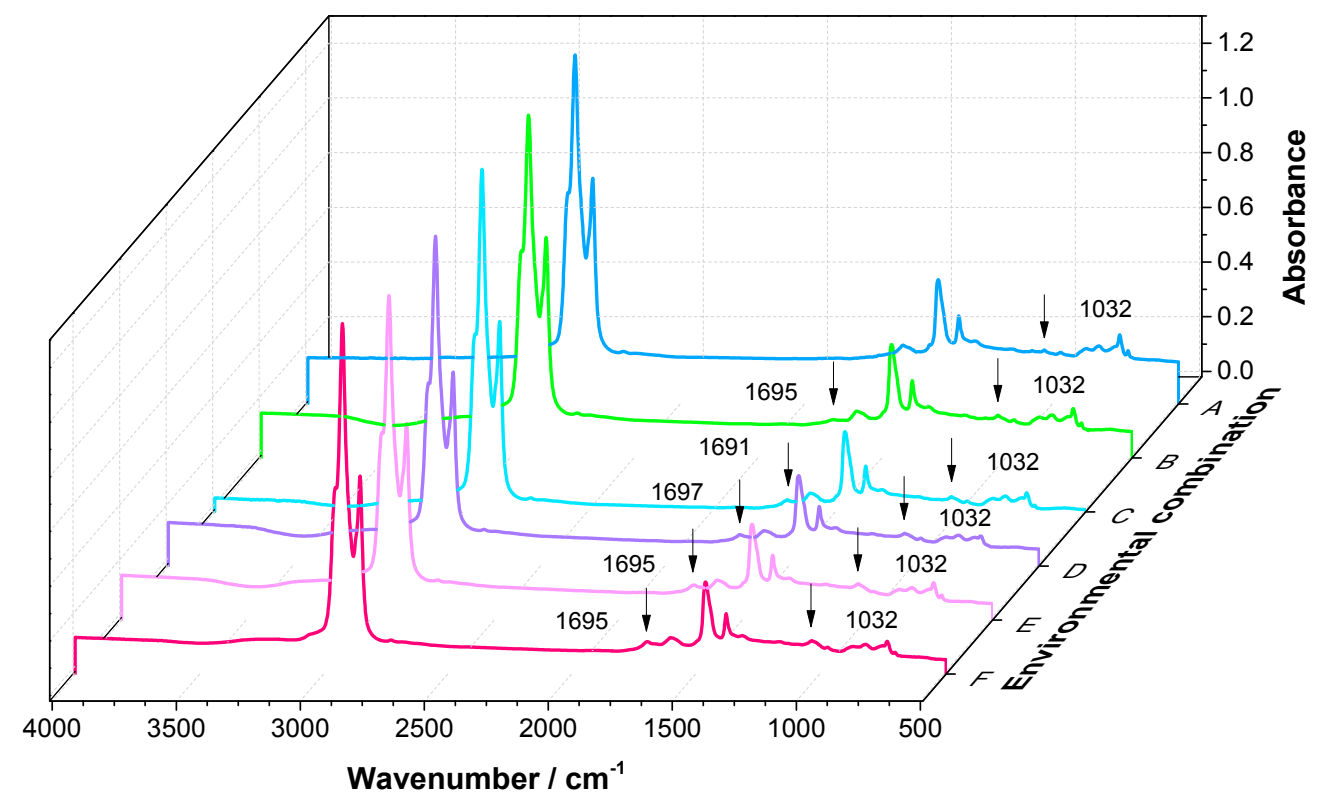

Figure 10. IR spectra of asphalt $\mathrm{T}$ under different environmental combinations.

$\mathrm{C}=\mathrm{O}$ and $\mathrm{S}=\mathrm{O}$ are the major functional groups formed during oxidative aging. Accordingly, the $\mathrm{C}=\mathrm{O}$ and $\mathrm{S}=\mathrm{O}$ indices can be used as indices to evaluate the oxidation degree of asphalts. They are computed as Equations (2) and (3) based on the absorption peak areas of $\mathrm{C}-\mathrm{H}$ bonds. The results are summarized in Table 6.

$$
\begin{gathered}
I_{C=O}=\frac{\text { Absorption peak area of } C=O\left(\text { centred around } 1700 \mathrm{~cm}^{-1}\right)}{\text { Absorption peak areas of } C-H\left(\text { centred around } 1460 \mathrm{~cm}^{-1}\right)} \\
I_{S=O}=\frac{\text { Absorption peak area of } S=O\left(\text { centred around } 1030 \mathrm{~cm}^{-1}\right)}{\text { Absorption peak areas of } C-H\left(\text { centred around } 1460 \mathrm{~cm}^{-1}\right)}
\end{gathered}
$$

where $I_{C=O}$ is the $\mathrm{C}=\mathrm{O}$ index, and $I_{S=O}$ is the $\mathrm{S}=\mathrm{O}$ index. 
According to Table 9, the $I_{C=O}$ of each asphalt increases with the combination of environmental factors. However, the rising tendency of $I_{S=O}$ is suppressed under combination E. Actually, $\mathrm{C}=\mathrm{O}$ and $\mathrm{S}=\mathrm{O}$ will decrease following dissolution in water. $\mathrm{C}=\mathrm{O}$ can still be obtained from the process of carbon conversion, but no enough sulfur remains for $\mathrm{S}=\mathrm{O}$. Furthermore, the relative changes in $I_{C=O}$ and $I_{S=O}$ indirectly reflect the antioxidant properties.

Table 9. Values of $\mathrm{C}=\mathrm{O}$ and $\mathrm{S}=\mathrm{O}$ indices.

\begin{tabular}{cccccccc}
\hline Sample & Index & A & B & C & D & E & F \\
\multirow{2}{*}{ Asphalt P } & $I_{C=O}$ & 0 & 0.018289 & 0.031278 & 0.070536 & 0.082277 & 0.095618 \\
& $I_{S=O}$ & 0.024649 & 0.043078 & 0.088656 & 0.150342 & 0.131924 & 0.141804 \\
\hline \multirow{2}{*}{ Asphalt R } & $I_{C=O}$ & 0 & 0.051451 & 0.071577 & 0.096944 & 0.111945 & 0.128721 \\
& $I_{S=O}$ & 0.041658 & 0.073521 & 0.075599 & 0.126110 & 0.115765 & 0.124667 \\
\hline \multirow{2}{*}{ Asphalt T } & $I_{C=O}$ & 0 & 0.046519 & 0.070505 & 0.090220 & 0.098583 & 0.109545 \\
& $I_{S=O}$ & 0.036079 & 0.072126 & 0.073580 & 0.093736 & 0.099961 & 0.114495 \\
\hline
\end{tabular}

The integral range of $\mathrm{C}=\mathrm{O}$ is $\left[1640 \mathrm{~cm}^{-1}, 1740 \mathrm{~cm}^{-1}\right]$; the integral range of $\mathrm{S}=\mathrm{O}$ is $\left[985 \mathrm{~cm}^{-1}, 1070 \mathrm{~cm}^{-1}\right]$; the integral range of $\mathrm{C}-\mathrm{H}$ is $\left[1400 \mathrm{~cm}^{-1}, 1500 \mathrm{~cm}^{-1}\right]$.

The changes in the two indices of both asphalts $\mathrm{R}$ and $\mathrm{T}$ are greater than those of asphalt $\mathrm{P}$, Nonetheless, the index values of asphalts $R$ and $T$ have changed relatively slightly throughout each aging process, which proves their remarkable antioxidant properties.

\section{Conclusions}

Based on the experimental results from the three kinds of asphalts influenced by different environmental combinations, the following conclusions can be drawn:

(1) Conventional property tests, including softening point, viscosity, creep stiffness, creep rate, and fatigue cracking factor, were conducted on asphalt samples. Results demonstrate that the aging characteristics of two kinds of rubber-modified asphalts improve with different pertinences, unlike virgin asphalt. Firstly, the resistant ability to high temperature of asphalt rubber rarely declines under water molecule action, whereas TOR asphalt rubber effectively avoids the degradation in resistance to high temperature induced by ultraviolet radiation. Secondly, the low-temperature resistance of asphalt rubber remains relatively stable under either water action or air pressure. Thirdly, asphalt rubber has superior resistance to traffic loading under ultraviolet radiation. In addition, TOR asphalt rubber has strong resistance to traffic loading in a water environment.

(2) Chemical analyses contribute to the determination of aging mechanism. The SEM images illustrate that the detrimental effects of multi-factor combinations lead to the rough surfaces of two kinds of rubber modified asphalts, and these correspond directly to asphalt decays. According to thermogravimetric analysis, the good thermal stability of three kinds of asphalts are confirmed by the similar TG curves observed in most environmental combinations. Based on the IR spectra, new characteristic functional groups are not detected during the different aging processes. Furthermore, the oxidation degrees of two kinds of asphalt rubbers change relatively slightly throughout each aging process, thus demonstrating the outstanding antioxidant properties of them.

(3) Lastly, aging characteristics in different environments can be reasonably considered in the rational application of asphalts. Asphalt rubber is suitable for hot and humid areas or low temperature areas, meanwhile TOR asphalt rubber is appropriate to intensive ultraviolet radiation regions and heavy traffic areas. 
Acknowledgments: The authors would like to acknowledge the financial support from the National Natural Science Foundation Committee of China (no. 51178409 and no. 51578480) and thank the Engineering Testing Centre of Yangzhou University for their supports in the experiment.

Author Contributions: Peng Xiao and Aihong Kang conceived and designed the experiments; Jiahui Zheng and Yingqian Wang performed the experiments; Yingqian Wang and Jiahui Zheng analyzed the data; Jiahui Zheng wrote the paper; and Lu Sun modified and provided comments on the paper.

Conflicts of Interest: The authors declare no conflict of interest. The founding sponsors had no role in the design of the study; in the collection, analyses, or interpretation of data; in the writing of the manuscript, and in the decision to publish the results.

\section{References}

1. Yildirim, Y. Polymer modified asphalt binders. Constr. Build. Mater. 2007, 21, 66-72. [CrossRef]

2. Liang, M.; Xin, X.; Fan, W.; Sun, H.; Yao, Y.; Xing, B. Viscous properties, storage stability and their relationships with microstructure of tire scrap rubber modified asphalt. Constr. Build. Mater. 2015, 74, 124-131. [CrossRef]

3. Soon-Jae, L.; Akisetty, C.K.; Amirkhanian, S.N. The effect of crumb rubber modifier (CRM) on the performance properties of rubberized binders in HMA pavements. Constr. Build. Mater. 2008, 22, 1368-1376. [CrossRef]

4. Wang, H.; You, Z.; Mills-Beale, J.; Hao, P. Laboratory evaluation on high temperature viscosity and low temperature stiffness of asphalt binder with high percent scrap tire rubber. Constr. Build. Mater. 2012, 26, 583-590. [CrossRef]

5. Liu, H.; Chen, Z.; Wang, W.; Wang, H.; Hao, P. Investigation of the rheological modification mechanism of crumb rubber modified asphalt (CRMA) containing TOR additive. Constr. Build. Mater. 2014, 67, 225-233. [CrossRef]

6. Ma, A. Research on Performance and cross Blend Mechanism of Microwave Radiant Crumb Rubber Modified Asphalt. Master's Thesis, Yangzhou University, Yangzhou, China, 2006.

7. Huang, Y.; Bird, R.N.; Heidrich, O. A review of the use of recycled solid waste materials in asphalt pavements. Resour. Conserv. Recycl. 2007, 52, 58-73. [CrossRef]

8. Lu, X.; Isacsson, U. Effect of ageing on bitumen chemistry and rheology. Constr. Build. Mater. 2002, 16, 15-22. [CrossRef]

9. Siddiqui, M.N.; Ali, M.F. Studies on the aging behavior of the Arabian asphalts. Fuel 1999, 78, $1005-1015$. [CrossRef]

10. Lin, J.; Hong, J.; Liu, J.; Wu, S. Investigation on physical and chemical parameters to predict long-term aging of asphalt binder. Constr. Build. Mater. 2016, 122, 753-759. [CrossRef]

11. Calabi-Floody, A.; Thenoux, G. Controlling asphalt aging by inclusion of byproducts from red wine industry. Constr. Build. Mater. 2012, 28, 616-623. [CrossRef]

12. Apeagyei, A.K. Laboratory evaluation of antioxidants for asphalt binders. Constr. Build. Mater. 2011, 25, 47-53. [CrossRef]

13. Wang, J. Study on Ageing Mechanism and Rheologic Behavior of Asphalt under Simulate Ultraviolet Environment; Harbin Institute of Technology: Harbin, China, 2008.

14. Zeng, W.; Wu, S.; Wen, J.; Chen, Z. The temperature effects in aging index of asphalt during UV aging process. Constr. Build. Mater. 2015, 93, 1125-1131. [CrossRef]

15. Lv, W. Design Principle and Method of Asphalt Mixture, 1st ed.; Tongji University Press: Shanghai, China, 2001; pp. 40-43. ISBN 7560822266.

16. Standard Test Methods of Bitumen and Bituminous Mixtures for Highway Engineering (JTG E20-2011); China Communications Press: Beijing, China, 2011; ISBN 9787114094682.

17. Li, P.; Zhang, Z.; Wang, B. Discussion on UV-light ageing characteristic and mechanism of asphalt. J. Zhengzhou Univ. Eng. Sci. 2008, 29, 96-100. [CrossRef]

18. Wu, S.; Pang, L.; Mo, L.; Qiu, J.; Zhu, G.; Xiao, Y. UV and thermal aging of pure bitumen-comparison between laboratory simulation and natural exposure aging. Road Mater. Pavement Des. 2008, 9, 103-113. [CrossRef]

19. Yamaguchi, K.; Sasaki, I.; Meiarashi, S. Photodegradation test of asphalt binder using pressed thin film samples. Can. J. Civ. Eng. 2005, 32, 1166-1169. [CrossRef] 
20. Bian, F.; Zhao, Y.; Huang, X.; Wang, Z. Experimental study of water aging on asphalt during service life of pavements. J. Southeast Univ. Engl. Ed. 2010, 26, 618-621. [CrossRef]

21. Solaimanian, M.; Anderson, D.; Hunter, D. Evaluation of Vestenamer Reactive Modifier in Crumb Rubber Asphalt; Pennsylvania Transportation Institute: Bellefonte, PA, USA, 2003.

22. Yin, J.; Tan, J. The observation and analysis of the surface solar ultraviolet radiation in Shanghai. J. Trop. Meteorol. 2006, 22, 86-90. [CrossRef] 